\title{
A CROSS-SECTIONAL STUDY EVALUATING THE KNOWLEDGE, ATTITUDE OF UNDERGRADUATE MEDICAL STUDENTS ABOUT PHARMACOVIGILANCE AND ADVERSE DRUG REACTION REPORTING AT A MEDICAL COLLEGE IN HYDERABAD
}

\author{
VIBHA RANI ${ }^{1 *}$, SHYAMALA R $^{2}$, SIMPSON GB ${ }^{1}$ \\ ${ }^{1}$ Department of Pharmacology, Malla Reddy Medical College for Women, Hyderabad, Telengana, India. ${ }^{2}$ Department of Microbiology, Malla \\ Reddy Medical College for Women, Hyderabad, Telengana, India. Email: vibha_udupi@yahoo.co.in
}

Received: 22 March 2017, Revised and Accepted: 12 April 2017

ABSTRACT

Objectives: Objectives of the study were (1) to evaluate the knowledge about pharmacovigilance and (2) to assess the attitude toward adverse drug reaction (ADR) reporting among undergraduate medical students.

Methods: It is a cross-sectional, questionnaire-based study conducted in the Department of Pharmacology, Malla Reddy Medical College for Women, Hyderabad, Telangana, among fifth term Bachelor of Medicine, Bachelor of Surgery students (136). The questionnaire consisted of 16 questions dealing with knowledge, awareness, attitude about pharmacovigilance and ADR reporting. Data were analyzed and presented as percentage among respondents.

Results: About $58.8 \%$ of students could not identify the proper definition of pharmacovigilance and $84.5 \%$ of undergraduates have not seen ADR form. It was agreed among $42.6 \%$ of students that ADR reporting is a professional obligation to them and $47.7 \%$ agreed that establishing ADR monitoring center in every hospital is compulsory.

Conclusions: Our study revealed that though the attitude toward pharmacovigilance was appreciable among the medical students; there lies an insufficient knowledge and awareness about pharmacovigilance. Continued medical education programs and workshops may be helpful in the future to increase awareness and consequently to improve the rate of spontaneous ADR reporting among these upcoming doctors.

Keywords: Pharmacovigilance, Adverse drug reaction, Spontaneous reporting, Undergraduate students, Knowledge, Attitude.

(c) 2017 The Authors. Published by Innovare Academic Sciences Pvt Ltd. This is an open access article under the CC BY license (http://creativecommons. org/licenses/by/4. 0/) DOI: http://dx.doi.org/10.22159/ajpcr.2017.v10i7.18633

\section{INTRODUCTION}

The World Health Organization (WHO) has defined pharmacovigilance as "the science and activities relating to the detection, assessment, understanding and prevention of adverse effects or any other possible drug-related problems" [1]. Although a new drug has to undergo various clinical and non-clinical trials, yet the need of pharmacovigilance becomes mandatory as the information generated from clinical trials is not sufficient to evaluate the safety of drugs with regard to adverse drug reaction (ADR) for its being limited to few number of patients, and the conditions for the use of medicines differ from that in clinical practice and for regular use by the patients [2]. The main objective of pharmacovigilance is that the drug molecule which has entered the market is safe for the treatment of various diseases of the general population who suffer from different medical conditions. Satisfactory reporting of suspected ADRs by health-care professionals is all important in this issue.

WHO definition of ADR is "a response to a drug which is noxious and unintended and which occurs at doses normally used in man for the prophylaxis, diagnosis or therapy of disease or for the modification of physiological function" [3]. Out of the several methods of detecting and analyzing ADRs, spontaneous reporting of ADR has contributed significantly to improved levels of pharmacovigilance. It plays an important role in the detection of ADRs, and many drugs with potential serious harmful effects have been withdrawn from the market due to it [4]. To boost spontaneous reporting by health-care providers, ADRs monitoring centers are being established in India under Pharmacovigilance Program of India (PvPI) [5]. Still pharmacovigilance is in its infancy phase in India. Lack of awareness among health-care professionals is one of the main reasons for this. Although studies reporting the level of awareness and practices of pharmacovigilance have been done in different parts of India [6-8], very few studies have focused this aspect in Telangana. Further, most of the studies have included health-care workers, but studies on awareness among undergraduate students are limited [9-11].

The Medical Council of India has recommended to teach ADR monitoring for undergraduate students [12]; to motivate the participation of health-care professionals in spontaneous reporting, it is very much essential to design strategies that modify both intrinsic (knowledge, attitude, and practices) and extrinsic (relationship between health professionals and their patients, the health system and the regulators) factors [13]. As future medical practitioners, medical students need to be well trained on how to recognize, prevent and report ADRs. Teaching pharmacovigilance to medical students makes them realize that all drugs can cause ADRs and it motivates them to participate in PvPI [14]. The right time to improve their knowledge about pharmacovigilance is mainly during the undergraduate course. In view of this, this study was undertaken to assess the awareness of pharmacovigilance and ADR reporting among fifth term medical undergraduate students at a medical college in Hyderabad. This would help us in planning interventions among this group of upcoming doctors.

\section{METHODS}

It is a cross-sectional, questionnaire-based survey conducted in the Department of Pharmacology, Malla Reddy Medical College for Women (MRMCW), Hyderabad, Telangana, among fifth term Bachelor of Medicine, Bachelor of Surgery (MBBS) students (136). The study tool 
Table 1: Knowledge of pharmacovigilance

\begin{tabular}{llll}
\hline Q.No. & Question & Response in \% (out of 136) \\
\cline { 3 - 4 } & & Correct & Wrong \\
\hline 1. & Definition of Pharmacovigilance & $41.1 \%(56)$ & $58.8 \%(80)$ \\
2. & A serious adverse drug event (ADR) in India should be reported to the regulatory body within & $39 \%(52)$ & $61 \%(84)$ \\
3. & Government regulatory body involved for drug safety issues in India & $86.7 \%(118)$ & $13.2 \%(18)$ \\
4. & The health-care professionals responsible for reporting ADR in a hospital is/are & $71.3 \%(97)$ & $28.6 \%(39)$ \\
5. & Where is the international center for monitoring ADR located? & $36.7 \%(50)$ & $63.2 \%(86)$ \\
6. & How to asses causality assessment of suspected ADR? & $43.3 \%(59)$ & $55.8 \%(76)$ \\
7. & Is Vigibase a WHO online database for reporting ADR? & $80.14 \%(109)$ & $19.85 \%(27)$ \\
\hline
\end{tabular}

ADR: Adverse drug reaction, WHO: World Health Organization

was a questionnaire which was designed from previous studies and suitably modified for our present setting. This questionnaire contains a total of 16 questions. Among the questions, 7 are related to knowledge and 2 questions are related to awareness about pharmacovigilance, both were of multiple choice type and 6 questions was for attitude, it was of modified Likert's-type scale by ticking one of the five alternatives (5 point scale) viz., strongly agree, agree, neither agree or disagree (neutral), disagree and strongly disagree. Oral consent was taken from the students before the study, and they were asked not to disclose their identity. 20 minutes was given to fill up the questionnaire. The study was approved by Institutional Ethics Committee, MRMCW, Hyderabad, Telangana. The data were collected and expressed in percentage using Microsoft Office Excel software.

\section{RESULTS}

The questionnaire contains a total of 16 questions. Among the questions, 7 are related to knowledge and 2 questions are related to awareness about pharmacovigilance and it was of multiple choice type and 6 questions was for attitude, it was of modified Likert's-type scale by ticking one of the five alternatives ( 5 point scale) viz., strongly agree, agree, neither agree or disagree (neutral), disagree and strongly disagree.

Table 1 shows knowledge of pharmacovigilance among undergraduate students. $58.8 \%$ of students could not identify the proper definition of pharmacovigilance, but $86.7 \%$ of students could tell that Central Drug Standard Control Organization (CDSCO) is the regulatory body for drug safety issues in India. $61 \%$ of students were not able to tell when a serious adverse drug event in India should be reported to the regulatory body in India. Among the students, only $36.7 \%$ of them were able to tell that International Centre for Reporting ADR is Uppsala (Fig. 1). Only $71.3 \%$ of students had knowledge that doctors, nurses, and pharmacists are the health-care professional responsible for ADR reporting (Fig. 2). Naranjo algorithm is the used to assess causality assessment of suspected ADR was answered correctly by $43.3 \%$ of students. $80.14 \%$ of them were able to make out that Vigibase is the WHO online database for reporting ADRs.

Table 2 shows awareness of pharmacovigilance among medical students. $59.55 \%$ of students could tell that a drug can be banned because of ADR. The students were asked to give an example for a drug banned because of ADR; the reply was thalidomide, phenylpropanolamine, fenfluramine, cisapride, phenformin, and valdecoxib. When asked whether they have seen ADR reporting form, $84.5 \%$ of students reported that they have not seen ADR reporting form.

Table 3 shows assessment of attitude by Likert's-type scale regarding ADR reporting among students. It was good to see that $42.6 \%$ of students strongly agreed to the fact that ADR reporting is a professional obligation to them. When asked whether establishing ADR monitoring center should be made compulsory in every hospital, $47.7 \%$ of them strongly agreed to the fact. $46.3 \%$ of students agreed to the fact that it is necessary to report ADR. Pharmacovigilance should be taught in detail to health-care professionals is strongly agreed among $53.6 \%$ of students. $39.7 \%$ felt ADR reporting is essential to reduce the cost
Table 2: Awareness of pharmacovigilance

\begin{tabular}{|c|c|c|c|}
\hline \multirow[t]{2}{*}{ Q.No. } & \multirow[t]{2}{*}{ Question } & \multicolumn{2}{|c|}{$\begin{array}{l}\text { Response in \% } \\
\text { (out of 136) }\end{array}$} \\
\hline & & Yes & No \\
\hline 1. & $\begin{array}{l}\text { Can a drug be banned because } \\
\text { of adverse drug reaction? If } \\
\text { yes, name the drug }\end{array}$ & $59.5 \%(81)$ & $40.4 \%(55)$ \\
\hline 2. & $\begin{array}{l}\text { Have you seen ADR reporting } \\
\text { form? }\end{array}$ & $15.4 \%(21)$ & $84.5 \%(115)$ \\
\hline
\end{tabular}

ADR: Adverse drug reaction

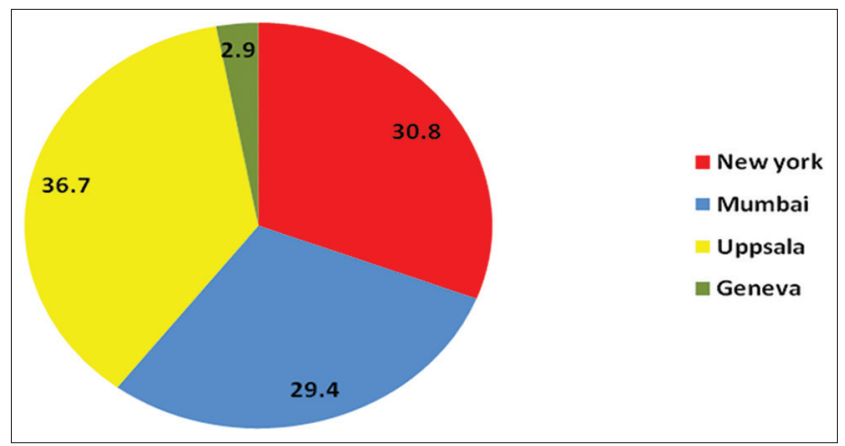

Fig. 1: International Center for monitoring adverse drug reaction - Data are represented in percentage (\%)

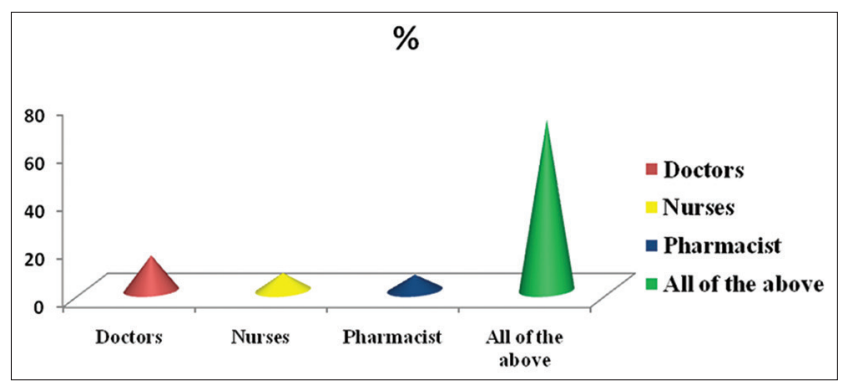

Fig. 2: Health-care professionals responsible for reporting adverse drug reaction in hospital - Data are represented in percentage (\%)

of medical care in India. It was strongly agreed by $46.3 \%$ of students that pharmacovigilance activities will help to reduce morbidity and mortality. $51.4 \%$ of students felt practicing pharmacovigilance will bring improvement in the quality of life.

\section{DISCUSSION}

ADR reporting is an integral part of pharmacovigilance and is important for patient care. Underreporting of ADR is a major threat to the success of pharmacovigilance program [15]. The ultimate aim of 
Table 3: Assessment of attitude regarding ADR reporting using Likert's-type scale

\begin{tabular}{|c|c|c|c|c|c|c|}
\hline Q.No. & Question & $\begin{array}{l}\text { Strongly } \\
\text { disagree (\%) }\end{array}$ & Disagree (\%) & Neutral (\%) & Agree (\%) & $\begin{array}{l}\text { Strongly } \\
\text { agree }(\%)\end{array}$ \\
\hline 1. & $\begin{array}{l}\text { Do you think ADR reporting is a professional } \\
\text { obligation for you? }\end{array}$ & $7(5.1)$ & $11(8)$ & $14(10.2)$ & $49(36)$ & $55(42.6)$ \\
\hline 2. & $\begin{array}{l}\text { Is establishing ADR monitoring center in } \\
\text { every hospital compulsory? }\end{array}$ & $1(0.7)$ & 0 & $12(8.8)$ & $58(42.6)$ & $65(47.7)$ \\
\hline 3. & Is it necessary to report ADR? & 0 & $3(2.2)$ & $7(5.1)$ & $63(46.3)$ & $63(46.3)$ \\
\hline 4. & $\begin{array}{l}\text { Do you think pharmacovigilance should be } \\
\text { taught in detail to health-care professionals? }\end{array}$ & 0 & $2(1.4)$ & $8(5.8)$ & $53(38.9)$ & $73(53.6)$ \\
\hline 5. & $\begin{array}{l}\text { ADR reporting is essential to reduce the cost } \\
\text { of medical care in India }\end{array}$ & $6(4.4)$ & $2(1.4)$ & $32(23.5)$ & $54(39.7)$ & $42(30.8)$ \\
\hline 6. & $\begin{array}{l}\text { Pharmacovigilance activities will help to } \\
\text { reduce the morbidity and mortality }\end{array}$ & $2(1.4)$ & 0 & $11(8)$ & $60(44.1)$ & $63(46.3)$ \\
\hline 7. & $\begin{array}{l}\text { Practicing pharmacovigilance will bring } \\
\text { improvement in the quality of life }\end{array}$ & $2(1.4)$ & $1(0.7)$ & $7(5.1)$ & $56(41.1)$ & $70(51.4)$ \\
\hline
\end{tabular}

pharmacovigilance is to ensure safe and rational use of medicine. The most important outcome of pharmacovigilance is the prevention of patients being affected unnecessarily by the negative consequences of pharmacotherapy [16].

In our study, $58.8 \%$ of students did not know WHO standard definition of pharmacovigilance though this topic was dealt to them briefly during their general pharmacology classes which are similar to studies done earlier $[17,18]$. However, the majority of students could tell CDSCO is the regulatory body for drug safety issues in India; the result of which is similar to other studies $[19,20]$. From our study, it was seen that a majority of students have not seen the ADR reporting form at all. Educational intervention is very much essential to these undergraduate students to get a good grasp of pharmacovigilance. Hence, this topic must be dealt separately during their theory classes and initiation must be made for inclusion how to fill ADR form and causality assessment of ADR in our practical syllabus. With regard to attitude toward ADR reporting, students response was satisfactory. The majority felt that pharmacovigilance should be taught in detail to health-care professionals and practicing it will bring improvement in the quality of life, which correlates with another study [21]. The students also felt that phamacovigilance will definitely help to reduce the morbidity, mortality and will bring improvement in the quality of life. $42.6 \%$ of students felt ADR reporting is a professional obligation to them which is similar to other studies [20]. In studies done among doctors by Thomas et al., Gupta and Udupa, 98\%, 80.9\% respectively, felt ADR reporting is a professional to them $[22,23]$. This difference in attitude between doctors and students might be because of increased awareness among doctors compared to undergraduate students.

Medical students who have real knowledge of pharmacovigilance are likely to provide more adequate health services in their future practice. So with a positive attitude toward ADR reporting, many interventions can be made in the students curriculum such as continued medical education, seminars, and workshops to strengthen the system and to improve the ADR reporting culture in our country so that students realize that all medicines can cause ADRs. The students can get an actual practical knowledge by visiting a pharmacovigilance center and by observing its functioning carefully. Even students of dental, nursing, pharmacy, and physiotherapy courses can be sensitized to spread the awareness about it. The result of this study is only a tip of iceberg with reference to the knowledge, awareness, and attitude of students toward pharmacovigilance. Many studies from different institutions of different geographical areas and different health-care professionals should be conducted in the future order to improvise the need for ADR reporting in India.

\section{CONCLUSION}

Our study suggested that though the attitude toward pharmacovigilance was appreciable among the medical students, there lies an insufficient knowledge and awareness about pharmacovigilance. Widening the teaching programs for students during their undergraduate training might provide a solution to strengthen ADR reporting system.

\section{ACKNOWLEDGMENT}

We thank all the students of 2014 batch MBBS students for participating in the study.

\section{REFERENCES}

1. Khurana A, Rastogi R, Gamperl HJ. A new era of drug safety - New EU pharmacovigilance (PV) legislation and comparison of PV in EU, US and India. Int J Pharm Pharm Sci 2014;6(7):15-21.

2. Kumar L. Pharmacovigilance/reporting adverse drug reactions: An approach to enhance health surveillance and extending market share by minimizing the chances of drug withdrawals. Int J Pharm Pharm Sci 2015;7(9):1-7

3. World Health Organization. International Drug Monitoring: The Role of National Centres. Report No: 498. Geneva, Switzerland: World Health Organization; 1972.

4. Wysowski DK, Swartz L. Adverse drug event surveillance and drug withdrawals in the United States, 1969-2002: The importance of reporting suspected reactions. Arch Intern Med 2005;165:1363-9.

5. Pharmacovigilance Programme of India 2010. CDSCO, Ministry of Health and Family Welfare, Government of India; 2010. Available from: http://www.cdsco.nic.in/pharmacovigilance.htm.

6. Amancharla MK, Choppara JV, Keelu RK, Kommavarapu P, Kotannagari VV. Study of awareness of pharmacovigilance among health care professionals \& medical students attached to a tertiary care hospital in Andhra Pradesh, India. Int J Curr Med Appl Sci 2015;5(2):63-7.

7. Ray D, Venugopal A. An evaluation of knowledge, attitude and practice of pharmacovigilance amongst the prescribers of a medical college hospital in North Eastern State of India: A cross sectional study. Indian J Pharm Pharmacol 2015;2(4):183-90.

8. Goyal M, Bansal M, Yadav S, Grover V, Anwal P. To assess the attitude, knowledge and practices of medical professionals about adverse drug reactions and their reporting in a teaching hospital. Indian J Clin Pract 2013;24(3):281-4

9. Rai S, Kumari VP, Shanbhag TV, Pai MR. Evaluation of knowledge and attitude of adverse drug reaction reporting among medical undergraduate students in a tertiary care hospital. World J Pharm Pharm Sci 2015;4(10):2085-9

10. Nadeem MN, Vaseem A, Maqdoom M. Across-sectional study evaluating the awareness of pharmacovigilance among MBBS interns of a teaching hospital in South India. Int $\mathrm{J}$ Basic Clin Pharmacol 2016;5(6):2468-75.

11. Kaikade SB, Pise ND. Knowledge and awareness about ADR reporting and pharmacovigilance among medical undergraduates. Int J Biomed Res 2016;7(5):295-6.

12. Desai CK, Iyer G, Panchal J, Shah S, Dikshit RK. An evaluation of knowledge, attitude, and practice of adverse drug reaction reporting among prescribers at a tertiary care hospital. Perspect Clin Res 2011;2(4):129-36 
13. Li Q, Zhang SM, Chen HT, Fang SP, Yu X, Liu D, et al. Awareness and attitudes of healthcare professionals in Wuhan, China to the reporting of adverse drug reactions. Chin Med J (Engl) 2004;117(6):856-61

14. Shankar PR, Subish P, Mishra P, Dubey AK. Teaching pharmacovigilance to medical students and doctors. Indian J Pharmacol 2006;38(5):316-9.

15. Kulkarni MD, Baig MS, Chandaliya KC, Doifode SM, Razvi SU, Sindhu NS. Knowledge attitude and practice of pharmacovigilance among prescribers of Government Medical College and Hospital, Arungabad (Maharashtra). Int J Pharmacol Ther 2013;3(3):10-8.

16. Palaian S, Ibrahim MI, Mishra P. Health professionals' knowledge, attitude and practices towards pharmacovigilance in Nepal. Pharm Pract (Granada) 2011;9(4):228-35.

17. Madhavrao C, Bai KM. Awareness of pharmacovigilance among dental interns. Eur J Biomed Pharm Sci 2015;2(60):193-6.

18. Sindhuja CH, Begum SK, Teja PS, Sudha P. Knowledge, attitude and behavior of community pharmacists towards adverse drug reactions. Int J Pharm Pharm Sci 2015;7(9):258-61.
19. Radhakrishnan R, Sudha V, Danturulu MV. An educational intervention to assess knowledge attitude practice of pharmacovigilance among health care professionals in an Indian tertiary care teaching hospital. Int J PharmTech Res 2011;3(2):678-92.

20. Deepak P, Nagaral JV. Awareness of pharmacovigilance among medical students. Int J Recent Trends Sci Technol 2014;13(2):262-5.

21. Sivadasan S, Sellappan M. A study on the awareness and attitude towards Pharmacovigilance and adverse drug reaction reporting among nursing students in a private university, Malaysia. Int J Curr Pharm Res 2015;7(1):84-9.

22. Thomas TM, Udaykumar P, Scandashree K. Knowledge, attitude and practice of adverse drug reaction reporting among doctors in a tertiary health care centre in South India. Int J Pharmacol Clin Sci 2013;2(3):82-8

23. Gupta P, Udupa A. Adverse drug reaction reporting and pharmacovigilance: Knowledge, attitudes and perceptions amongst resident doctors. J Pharm Sci Res 2011;3(2):1064-9. 